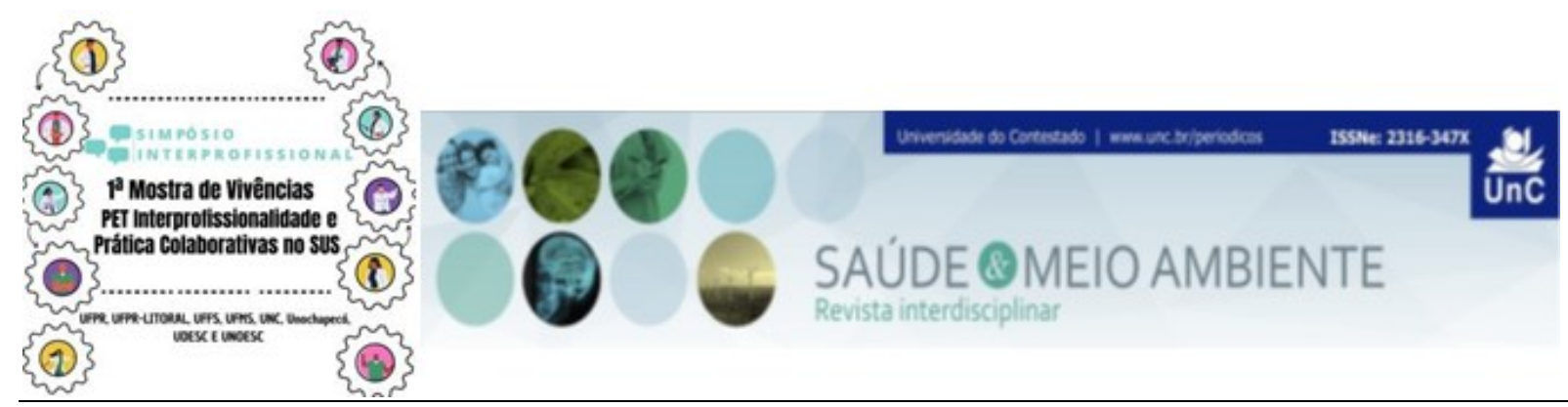

\title{
O USO DO FACEBOOK PELO PET SAÚDE LITORAL NA EDUCAÇÃO E COMUNICAÇÃO EM SAÚDE NO ENFRENTAMENTO À COVID-19 ${ }^{1}$
}

Projeto 93

\author{
Marina Teani Moreira ${ }^{2}$ \\ Tainá Rinas Mélo ${ }^{3}$ \\ Michele Cristina Dullius ${ }^{4}$ \\ Vinício Oliveira da Silva ${ }^{5}$ \\ Rafaela Carvalho de Amorim ${ }^{6}$ \\ Jéssica Teixeira Gonçalves ${ }^{7}$
}

RESUMO

Introdução: Sabe-se que a falta de acesso à informações de qualidade e a elevada disseminação de fake news pode representar grave impacto para a saúde no contexto da pandemia de COVID-19. Nesse sentido, o processo de educação em saúde, utilizando mídias sociais, surge como alternativa para contribuir com a difusão de informações técnicas de qualidade, atualizadas e de conteúdo acessível, considerando que as medidas de distanciamento social impulsionam o aumento de acesso online (Scheifer, 2020). Assim, o projeto de extensão "PETSaúde/Interprofissionalidade" da Universidade Federal do Paraná, setor Litoral, em parceria com a Secretaria Municipal de Saúde de Paranaguá e em consonância com as medidas de distanciamento social, intensificou as ações de educação e comunicação sobre a saúde para o combate à COVID-19 por meio da página "PET Saúde Litoral", no Facebook. Objetivo: Analisar o envolvimento da comunidade a partir das publicações desenvolvidas pelo PET-Saúde em sua página do Facebook, no período pré e pós implementação de medidas de enfrentamento ao Coronavírus adotadas pelo Governo do Estado do Paraná, decreto nº 4230, o qual suspendeu as

${ }^{1}$ Fonte de financiamento: Programa de Educação pelo Trabalho para a Saúde - PET

Saúde/Interprofissionalidade 2019-2021 (Edital no 10 de 23 de julho de 2018, Ministério da

Saúde/Secretaria de Gestão do Trabalho e da Educação na Saúde).

${ }^{2}$ Bolsista. Estudante do curso de Serviço Social da Universidade Federal do Paraná. Paraná. Brasil.

E-mail: marina.teani@ufpr.br.

${ }^{3}$ Docente do Curso de Saúde Coletiva da Universidade Federal do Paraná, Setor Litoral. . Paraná.

Brasil. E-mail: ribasmelo@ufpr.br.

${ }^{4}$ Bolsista PET Saúde. Estudante do Curso de Bacharel em Saúde Coletiva da Universidade Federal

do Paraná, Setor Litoral. Paraná. Brasil. E-mail: mcdullius@gmail.com.

${ }^{5}$ Tutor e coordenador de equipe. Docente do curso de Saúde Coletiva da Universidade Federal do

Paraná, Setor Litoral. Paraná. Brasil. E-mail: viniciooliveira@ufpr.br.

${ }^{6}$ Preceptora PET Saúde. Nutricionista da Prefeitura Municipal de Paranaguá. Paraná. Brasil. E-mail: rafaela.c.amorim@hotmail.com.

${ }^{7}$ Preceptora PET Saúde. Psicóloga da Prefeitura Municipal de Paranaguá. Paraná. Brasil. E-mail: jessitxgon@hotmail.com. 
aulas presenciais em escolas e universidades públicas estaduais, entre outras (Paraná, 2020). Metodologia: Foram analisados dados de interação na plataforma Facebook, referente ao mês de fevereiro de 2020 - período que antecede as medidas para o enfrentamento ao Coronavírus no Paraná - e o mês de abril de 2020 (após decreto). A partir desta ferramenta (Facebook Business: Visão Geral), foi possível verificar comparativos dos meses supracitados referentes a: 1 . Reações: Curtidas e outras maneiras de as pessoas reagirem às publicações da página e; 2 . Alcance Total: O número de pessoas que viram qualquer conteúdo da ou sobre a Página (Facebook, 2020). Resultados: O item Reações demonstra que a maior interação do público com as publicações da página, no mês de fevereiro, foi de apenas 2 curtidas (cliques em "curtir") no dia 4, ultrapassando apenas o dia 5 de fevereiro, que totalizou somente 1 clique em "amei". Já a métrica de Alcance Total demonstra um recorde mensal de visualizações no dia 3 de fevereiro, com o total de 44 acessos no dia. Houveram mais acessos no mês de abril, o qual contou com 681 visualizações no dia de maior acesso (15 de abril) e um recorde mensal de 49 reações (41 "curtir", 7 "amei" e 1 "triste") no mesmo dia. A soma dos valores diários de Alcance Total resulta em 134 acessos no mês de fevereiro, contra 3.274 acessos no mês de abril de 2020. Considerações Finais: $O$ aumento percentual do Alcance Total de abril em comparação ao mês de fevereiro aponta um crescimento de mais de $2.344 \%$ e nos confirma: o aumento expressivo no alcance das publicações da página "PET Saúde - Litoral" no período de distanciamento social; e a importância do uso dessa ferramenta como meio de comunicação para o fomento da educação social na saúde, a popularização das ciências e o combate à fake news.

Palavras-chave: Coronavírus. Acesso à Informação. Rede Social.

\section{REFERÊNCIAS}

1. Scheifer V. Tráfego da internet brasileira na pandemia: quais foram os impactos?

Tecmundo [internet]. 2020 jun [acesso em: 29 jul 2020]. Disponível em:

https://www.tecmundo.com.br/internet/154628-trafego-internet-brasileirapandemia-impactos.htm

2. Paraná. Decreto $n^{\circ} 4.230$, de 16 de março de 2020. Dispõe sobre as medidas para enfrentamento da emergência de saúde pública de importância internacional decorrente do Coronavírus - COVID-19. Diário Oficial do Estado do Paraná. 16 mar 2020. Seção 1:3. [acesso em 29 jul 2020]. Disponível em: http://www.cedca.pr.gov.br/arquivos/File/2020/DecretoEstadual4230_COVID19.pd f.

3. Facebook [internet]. Business: PET Saúde Litoral. [acesso em 29 jul 2020]. Disponível em:

https://business.facebook.com/petsaudelitoral/insights/?section=navReach 